\title{
PSA-NCAM is expressed in immature, but not recently generated, neurons in the adult cat cerebral cortex layer II
}

\author{
Emilio Varea1 , Maria Belles' , Sandra Vidueira', José M. Blasco-lbáñez', Carlos Crespo ', Ángel M. Pastor ${ }^{2}$ \\ and Juan Nacher ${ }^{*}$
}

1 Neurobiology Unit and Program in Basic and Applied Neurosciences, Department of Cell Biology, Universitat de València, València, Spain

2 Facultad de Biología, Departamento de Fisiología y Zoología, Universidad de Sevilla, Sevilla, Spain

Edited by:

Gerd Kempermann, Center for

Regenerative Therapies, Germany

Reviewed by:

Luca Bonfanti, University of Turin, Italy

Sebastien Couillard-Despres,

Paracelsus Medical University

Salzburg, Austria

*Correspondence:

Juan Nacher, Neurobiology Unit,

Department of Cell Biology, Universitat de València, Dr. Moliner, 50, Burjassot

46100, Spain.

e-mail: nacher@uv.es
Neuronal production persists during adulthood in the dentate gyrus and the olfactory bulb, where substantial numbers of immature neurons can be found. These cells can also be found in the paleocortex layer II of adult rodents, but in this case most of them have been generated during embryogenesis. Recent reports have described the presence of similar cells, with a wider distribution, in the cerebral cortex of adult cats and primates and have suggested that they may develop into interneurons. The objective of this study is to verify this hypothesis and to explore the origin of these immature neurons in adult cats. We have analyzed their distribution using immunohistochemical analysis of the polysialylated form of the neural cell adhesion molecule (PSA-NCAM) and their phenotype using markers of mature neurons and different interneuronal populations. Additionally, we have explored the origin of these cells administering $5^{\prime}$ bromodeoxyuridine ( $5^{\prime} \mathrm{BrdU}$ ) during adulthood. Immature neurons were widely dispersed in the cerebral cortex layers II and upper III, being specially abundant in the piriform and entorhinal cortices, in the ventral portions of the frontal and temporoparietal lobes, but relatively scarce in dorsal regions, such as the primary visual areas. Only a small fraction of PSA-NCAM expressing cells in layer Il expressed the mature neuronal marker NeuN and virtually none of them expressed calcium binding proteins or neuropeptides. By contrast, most, if not all of these cells expressed the transcription factor Tbr-1, specifically expressed by pallium-derived principal neurons, but not CAMKII, a marker of mature excitatory neurons. Absence of PSA-NCAM $/ 5^{\prime}$ BrdU colocalization suggests that, as in rats, these cells were not generated during adulthood. Together, these results indicate that immature neurons in the adult cat cerebral cortex layer II are not recently generated and that they may differentiate into principal neurons.

\section{INTRODUCTION}

The production of new neurons in the adult mammalian CNS is mainly restricted to the subventricular zone (SVZ) surrounding the lateral ventricles and the subgranular zone (SGZ) of the hippocampal dentate gyrus. Consequently, immature neurons can be found in the olfactory bulb and in the granular layer of the dentate gyrus, the destination regions of the neurons produced in the SVZ and in the SGZ respectively (see Kempermann, 2005 for review). Surprisingly, the presence of immature neurons has also been detected in the layer II of the paleocortex of rodents. These cells are characterized by the expression of molecules related to neuronal development or plasticity, such as the microtubule associated protein doublecortin (DCX) or the polysialylated form of the neural cell adhesion molecule (PSA-NCAM), ultrastructural features typical of immature neurons and a virtual absence of synaptic input (Gomez-Climent et al., 2008, 2010b). The location of these immature neurons is similar in mice (Shapiro et al., 2007b; Nacher et al., 2010), but in mammals with larger cerebral cortices, such as guinea pigs, rabbits, cats, primates, and humans, they have a more widespread distribution (Luzzati et al., 2008; Xiong et al., 2008; Cai et al., 2009). In adult cats, DCX expressing cells in layers II and upper III, can be found dispersed throughout the cerebral cortex, being specially abundant in the entorhinal cortex and in the ventral portions of the frontal and temporoparietal lobes, but relatively scarce in dorsal regions, such as the primary visual areas (Cai et al., 2009).

An intriguing characteristic of the cells expressing immature neuronal markers in cortical layer II is their progressive disappearance during aging. Their number is strongly reduced in 1-year-old rats and they are almost absent in 2-year-old rats (Abrous et al., 1997; Murphy et al., 2001; Varea et al., 2009); similar results have been observed in the cerebral cortex of guinea pigs (Xiong et al., 2008), cats (Cai et al., 2009), and primates (Cai et al., 2009; Zhang et al., 2009). Consequently, these immature neurons might die during aging or they might differentiate into mature neurons. Since there is no evidence of substantial number of dying cells in the cortical layer II of different mammals, including cats (Friedman and Price, 1986; Xiong et al., 2008; Sarma et al., 2010), the second possibility appears more likely. If these immature neurons progressively differentiate, they might become principal or inhibitory neurons. Different studies have shown that the majority of these immature neurons express transcription factors specific of cortical excitatory neurons and have failed to find expression of interneuronal markers in them (Gomez-Climent et al., 2008; Luzzati et al., 2008). However, 
other studies have found that a subpopulation of cells in layer II expressing low levels of DCX were immunoreactive for different markers of interneurons (Cai et al., 2009). In particular, faint DCX immunoreactive cells were reported in the cortical layer II of adult cats, and said to co-express parvalbumin, calbindin, somatostatin, and nitrinergic markers, but not calretinin. Moreover, many of these DCX low-expressing cells were also found in deeper cortical layers showing an interneuronal phenotype (Cai et al., 2009).

A recent study in rats has shown that most immature neurons in cortical layer II have been generated during embryonic development but not during early postnatal development or during adulthood (Gomez-Climent et al., 2008). However, their time of origin is not known in cats.

In the present study we analyze the population of immature neurons in the layer II of the cerebral cortex of adult cats using PSANCAM immunohistochemistry. We also explore their putative fate using different markers of excitatory and inhibitory neurons and we study whether these cells are generated during adulthood using 5 'BrdU labeling. Since we have recently found that PSA-NCAM is expressed in a subpopulation of interneurons in the rodent and human cerebral cortex, specially in deep layers (Varea et al., 2005, 2007; Gomez-Climent et al., 2010a), we also study the distribution and phenotype of these cells in adult cats.

\section{MATERIALS AND METHODS ANIMAL TREATMENTS AND HISTOLOGY}

Eight adult cats, 18-24 months old and weighing $2.0-2.5 \mathrm{~kg}$ were obtained from authorized suppliers (Servicio de Animales de Experimentación, Universidad de Córdoba, Córdoba, Spain) were used in this experiment. All animals were used to study PSA-NCAM expression and its colocalization with several cellular markers using immunohistochemistry. A subset of four cats were used for double PSA-NCAM $/ 5^{\prime}$ BrdU immunohistochemistry. These animals received two injections, one every $24 \mathrm{~h}$, of 5 'BrdU (Sigma-Aldrich, $50 \mathrm{mg} / \mathrm{kg}$, i.p.) and were sacrificed 20 days $(n=2)$ or 60 days $(n=2)$ after the last injection. All animal experimentation was conducted in accordance with Directive 2010/63/EU of the European Parliament and of the Council of 22 September 2010 on the protection of animals used for scientific purposes and was approved by the Committee on Bioethics of the Universitat de València.

Cats were perfused transcardially under deep sodium pentobarbital anesthesia (50 mg/kg, i.p.), with saline and then $4 \%$ paraformaldehyde in sodium phosphate buffer $0.1 \mathrm{M}, \mathrm{pH}$ 7.4 (PB). After perfusion, the brains were extracted and cryoprotected with $30 \%$ sucrose in PB. Coronal sections $(50 \mu \mathrm{m})$ were obtained with a sliding microtome and stored at $-20^{\circ} \mathrm{C}$ in $30 \%$ glycerol; $30 \%$ ethylene glycol, 40\% PB until used.

\section{PSA-NCAM IMMUNOHISTOCHEMISTRY}

Tissue was processed "free-floating" for immunohistochemistry as follows. Briefly, sections were incubated for $1 \mathrm{~min}$ in an antigen unmasking solution $\left(0.01 \mathrm{M}\right.$ citrate buffer, $\mathrm{pH}$ 6) at $100^{\circ} \mathrm{C}$. After cooling down the sections to room temperature they were incubated with $10 \%$ methanol, $3 \% \mathrm{H}_{2} \mathrm{O}_{2}$ in phosphate buffered saline (PBS) for 10 min to block endogenous peroxidase activity. After this, sections were treated for $1 \mathrm{~h}$ with $5 \%$ normal donkey serum (NDS; Jackson Laboratories) in PBS with $0.2 \%$ Triton-X100 (Sigma) and were incubated overnight at room temperature in mouse monoclonal Men-B anti-PSA-NCAM antibody (1:1400, Abcys). This antibody recognizes exclusively the polysialic acid (PSA; Rougon et al., 1986), but since in the adult CNS most, if not all, PSA expression is associated to NCAM, it is frequently denominated anti-PSA-NCAM (Rutishauser, 2008). After washing, sections were incubated for $30 \mathrm{~min}$ with donkey anti-mouse IgM biotinylated antibody (Jackson Laboratories, 1:250), followed by an avidin-biotin-peroxidase complex (ABC, Vector Laboratories) for $30 \mathrm{~min}$ in PBS. Color development was achieved by incubating with 3,3'-diaminobenzidine tetrahydrochloride (DAB, Sigma) for 4 min. PBS containing $0.2 \%$ Triton-X100 and $3 \%$ NDS was used for primary and secondary antibodies dilution.

Pretreatment of the anti-PSA-NCAM antibody with $\alpha-2,8$ linked sialic polymer (Colominic acid, Sigma) overnight or the primary antibody omission during the immunohistochemistry prevented labeling in every cortical region studied.

\section{DOUBLE IMMUNOFLUORESCENCE}

In order to characterize the phenotype of PSA-NCAM immunoreactive cells, we have performed double immunohistochemistry using an anti-PSA-NCAM antibody and antibodies against different neuronal markers. In general, sections were processed as described above, but the endogenous peroxidase blocking was omitted. The sections were incubated overnight with mouse monoclonal IgM anti-PSA-NCAM antibody (Men-B, Abcys; 1.1400) and one of the following primary IgG antibodies: monoclonal mouse anti-Neuronal nuclear antigen (NeuN, Millipore; 1:100); monoclonal mouse antiglutamate decarboxylase (GAD67, Millipore; 1:1000); polyclonal goat anti-doublecortin (DCX, 1:500; Santa Cruz Biotechnology); polyclonal rabbit anti-cyclic nucleotide-gated cation channel (CNGA3, Alomone Labs; 1:500); monoclonal mouse anti-Ca2+/calmodulin dependent protein kinase II (CaMKII, Millipore; 1:200); polyclonal rabbit anti-T-box brain 1 (Tbr-1, Abcam; 1:500), monoclonal mouse anti-calbindin-D28K (Cb, Sigma; 1:1000); polyclonal rabbit anti-calretinin (Cr, Swant; 1:2500); polyclonal rabbit anti-parvalbumin (Pv, Swant; 1:2000); monoclonal mouse anti-cholecystokinin (CCK, Cure; 1:1000); polyclonal rabbit anti-vasoactive intestinal peptide (VIP, kindly provided by Dr. T. J. Görcs; 1:1000; Lantos et al., 1995); polyclonal rabbit anti-neuropeptide Y (NPY, kindly provided by Dr. T. J. Görcs; 1:1000; Csiffary et al., 1990); polyclonal rabbit anti-somatostatin (SST, Dako, 1:500); monoclonal mouse anti-nitric oxide synthase neural (nNOS, Sigma; 1:1000) After washing, sections were incubated with donkey anti-mouse IgM, donkey anti-mouse IgG or donkey anti-rabbit IgG secondary antibodies conjugated with Alexa 488 or Alexa 555 (Molecular Probes, 1:200) in PBS containing $0.2 \%$ Triton X-100 and 3\% NDS. Pretreatment of the anti-DCX antibody with its antigenic peptide, or the primary antibody omission during the immunohistochemistry prevented all the DCX labeling in every cortical region studied.

\section{PSA-NCAM/5'BrdU IMMUNOHISTOCHEMISTRY}

In order to check whether PSA-NCAM immunoreactive cells in the cortical layer II were recently generated, we have performed double PSA-NCAM $/ 5^{\prime}$ BrdU immunohistochemistry in the sections from the cats injected with $5^{\prime} \mathrm{BrdU}$. Sections were treated for $60 \mathrm{~min}$ at 
$60^{\circ} \mathrm{C}$ in PB. Denaturation of DNA was achieved by treating the sections for $30 \mathrm{~min}$ with $2 \mathrm{M} \mathrm{HCl}$ in $\mathrm{PB}$ at room temperature. Then, sections were processed as above, using monoclonal rat IgG anti5’BrdU (Immunologicals Direct, 1:200) and monoclonal mouse IgM anti-PSA-NCAM (Men-B, Abcys, 1:1400). Secondary antibodies were anti-mouse IgM and anti-rat IgG secondary antibodies generated in donkey and conjugated with Alexa 488 or Alexa 555.

\section{OBSERVATION AND QUANTIFICATION OF DOUBLE-LABELED CELLS}

All sections processed for fluorescent immunohistochemistry were mounted on slides and coverslipped using DakoCytomation fluorescent mounting medium (Dako). Then, the sections were observed under a confocal microscope (Leica TCS-SPE).Z-series of optical sections ( $1 \mu \mathrm{m}$ apart) were obtained using sequential scanning mode. These stacks were processed with LSM 5 Image Browser software. A 1-in-10 series of telencephalic sections from each animal $(n=8)$ were double-labeled as described. Fifty immunoreactive cells were analyzed in each case to determine the co-expression of PSA-NCAM and the markers of mature neurons, interneurons, or principal neurons described above. All percentages are expressed as the average \pm the SE of the mean.

\section{RESULTS \\ SUBTYPES AND DISTRIBUTION OF PSA-NCAM EXPRESSING CELLS IN THE ADULT CAT CEREBRAL CORTEX}

Polysialylated form of the neural cell adhesion molecule immunoreactivity was distributed throughout the cortical neuropil as well as on certain cell bodies. As a general feature, PSA-NCAM immunoreactive neuropil appeared more intense in layers III and $\mathrm{V}-\mathrm{VI}$, resembling the distribution observed in rodents (Varea et al., 2005) and humans (Varea et al., 2007). Differences in the extension of the immunoreactive area reflected different extensions of the layers in the different subdivisions of the cerebral cortex. The intensity of immunostaining was similar in layers III and V-VI, although in the deeper bands a gradient could be observed, being higher the intensity in superficial layer $\mathrm{V}$.

Two different populations of PSA-NCAM expressing cells could be found in the adult cat cerebral cortex. One of these populations ("S" cells) was composed by small cells, which usually displayed unipolar morphology, although some bipolar cells could also be found. Most of these cells had the morphology of those described as tangled cells in the rodent cerebral cortex (Gomez-Climent et al., 2008). These S cells were widely distributed in all the extension of the cerebral cortex (Figure 1), but always appeared concentrated in a band comprising layer II and upper layer III (in order to simplify the description of these cells we will refer to them as present in layer II). Although this band could be observed in all the subdivisions of cat cerebral cortex, PSA-NCAM expressing cells were most abundant in temporal areas, such as the entorhinal and piriform cortices (Figures 1 and 2A). By contrast, they were relatively scarce in dorsal regions, such as the primary visual areas. These results on the distribution of PSA-NCAM expressing cells in layer II of the cerebral cortex of adult cats are very similar to those described by Cai et al. (2009), using DCX immunohistochemistry. The majority of PSANCAM expressing S cells in layers II were small (around $12 \mu \mathrm{m}$ soma diameter) and showed processes with highly irregular trajectories, usually restricted to layer II (Figures 2B,C). These cells resembled

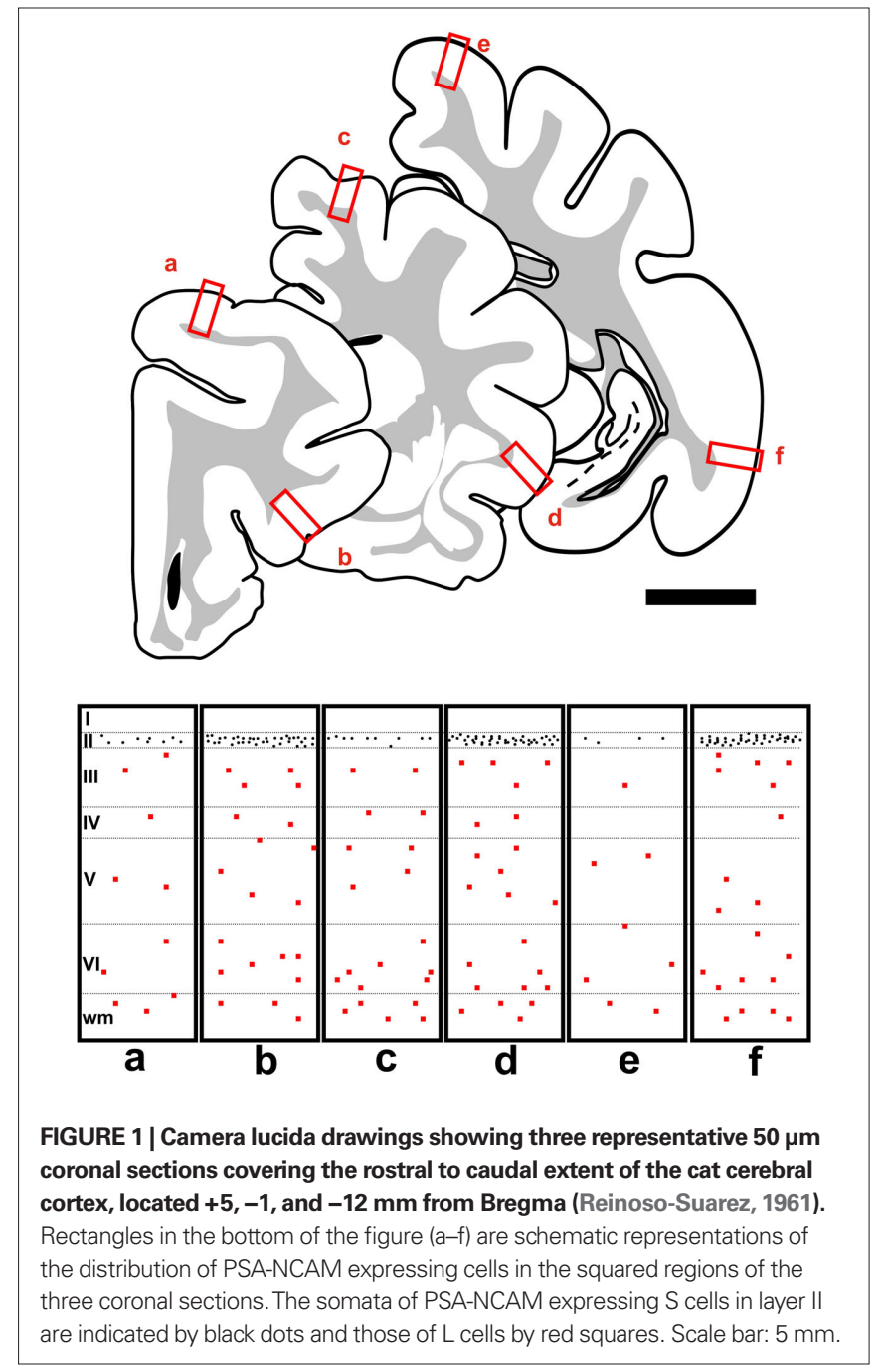

those denominated as tangled cells in the rat cerebral cortex. There were also some larger PSA-NCAM expressing S cells in the layer II (around $18 \mu \mathrm{m}$ soma diameter), which usually displayed one or two long dendrites expanding into layer I and resembled those identified as semilunar-pyramidal transitional neurons in rats (GomezCliment et al., 2008). Additionally, cells with mixed characteristics of both tangled cells and semilunar-pyramidal transitional neurons could be found. In the temporal cortex, abounding specially in the entorhinal cortex, thick vertical immunoreactive processes could be observed traversing all its layers. Many small and round PSA-NCAM immunoreactive somata could be seen apposed to these processes.

The other population ("L" cells) was composed by large cells, many of which resembled the PSA-NCAM expressing interneurons described in different cortical regions of adult rats (Nacher et al., 2002a,b; Varea et al., 2005; Gomez-Climent et al., 2010a). They were big multipolar cells (around $21 \mu \mathrm{m}$ soma diameter), which displayed long straight processes and resembled typical cortical interneurons (Figure 2D). These L cells could be found normally in the deeper layers of the cerebral cortex, although they were occasionally present in layer I, they were virtually absent from layer II (Figure 1). PSANCAM expressing L cells could be found in every cortical region, including the different subdivisions of the hippocampus. 


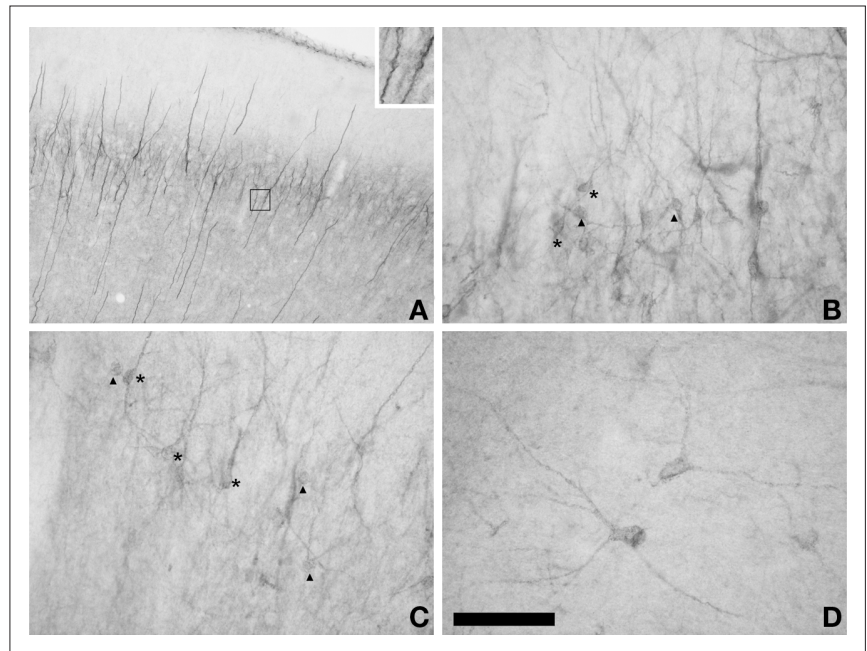

FIGURE 2 | Distribution of PSA-NCAM IR cells in the cat cerebral cortex. (A) Panoramic view of PSA-NCAM expression in the cat temporal cortex showing the presence of a dense band of immunostained cells in layer II. Note the characteristic vertical processes located in this cortical region. Inset in top right of the photograph shows two vertical processes to which three PSA-NCAM expressing small round somata are apposed. $(\mathbf{B}, \mathbf{C})$ Detailed view of PSA-NCAM immunoreactive cells in layer II of cat temporal cortex. Observe the different morphologies displayed by $\mathrm{S}$ cells: tangled (arrowheads) and semilunar-pyramidal transition cells (asterisks). (D) PSA-NCAM expressing L cells in deep layers of the cerebral cortex displaying multipolar or bipolar morphology. Scale bars: $300 \mu \mathrm{m}$ for (A), $60 \mu \mathrm{m}$ for (B-D). Inset in (A) is a 3x magnification of the boxed area.

\section{PHENOTYPE OF PSA-NCAM EXPRESSING S CELLS IN THE CEREBRAL CORTEX OF THE ADULT CAT \\ PSA-NCAM expressing S cells in cortical layer II express markers of immature neurons}

Most PSA-NCAM expressing S cells in cortical layer II, including all the subpopulations described in the precedent section, were also immunoreactive for doublecortin (95.8 $\pm 2.6 \%$; Figure 3A). They also expressed the $\mathrm{A} 3$ subunit of the cyclic nucleotide-gated ion channel (CNGA3; $93.8 \pm 2.4 \%$; Figure 3B), which is strongly expressed by migrating neuroblasts of the rostral migratory stream (RMS; Gutierrez-Mecinas et al., 2007) and by immature neurons in the layer II of the cortex of adult rats (Gomez-Climent et al., 2008).

\section{PSA-NCAM expressing S cells in cortical layer II do not express markers of mature neurons or interneurons and appear to have an excitatory fate}

Only a minor population of PSA-NCAM expressing S cells in cerebral cortex layer II expressed NeuN (20.5 \pm 1.3\%; Figure 3C). Moreover, in most of these immunoreactive nuclei the expression was faint, specially in those corresponding to tangled cells. NeuN immunoreactivity was usually more intense in the nuclei of the larger PSA-NCAM expressing cells.

Most, if not all, PSA-NCAM expressing $S$ cells in the cortical layer II expressed the transcription factor Tbr-1 (95.5 \pm 3.2 ; Figure $4 \mathrm{~A}$ ), which is specifically expressed by pallium-derived principal neurons. However, these cells did not express $\mathrm{Ca}(2+)$ / CaM-dependent protein kinase II (CAMKII), a marker of mature principal neurons (Figure 4B).
Polysialylated form of the neural cell adhesion molecule expressing S cells in layer II did not express markers of interneurons, such as GAD67, calbindin, calretinin, parvalbumin, vaso-intestinal peptide (VIP), neuropeptide Y, cholecystokinin, somatostatin, or the neural isoform of the nitric oxide synthase (nNOS; Figure 5).

\section{PSA-NCAM expressing cells are not recently generated}

Although in the two groups of animals studied (adult cats injected with 5'BrdU and sacrificed 20 or 60 days later) some scarce 5'BrdU labeled nuclei were found in layer II (many of them appeared in pairs), we never found any of them, neither in the 20-days group nor in the 60-days group, located inside a PSA-NCAM expressing soma. PSA-NCAM immunoreactive cells displaying a 5'BrdU labeled nucleus could be found in areas with known adult neurogenic activity. We also failed to find any PSA-NCAM expressing L cell displaying a $5^{\prime} \mathrm{BrdU}$ positive nucleus.

\section{Phenotype of PSA-NCAM expressing L cells in the cerebral cortex of the adult cat}

All PSA-NCAM expressing L cells analyzed in the cerebral cortex of adult cats were immunoreactive for the protein NeuN (Mullen et al., 1992), suggesting that they were mature neurons (Figure 6A). The mature phenotype of these L neurons was also supported by the complete lack of DCX expression. Moreover, we did not observe any cell with similar characteristics to those of PSA-NCAM expressing $\mathrm{L}$ cells displaying high or low levels of DCX immunoreactivity in the deep layers of the cerebral cortex.

Following previous studies in rodents (Gomez-Climent et al., 2010a), we tested several markers for different neuronal populations in order to characterize the PSA-NCAM immunoreactive neurons outside layer II in the cat cerebral cortex. None of these cells expressed CAMKII (Figure 6B). By contrast, we found that $47.8 \pm 3.7 \%$ of PSA-NCAM immunoreactive $\mathrm{L}$ neurons displayed also glutamate decarboxylase-67 (GAD67) immunoreactivity (Figure 6C). We also analyzed whether PSA-NCAM immunoreactive L neurons expressed any of the calcium binding proteins used as markers of different interneuronal subpopulations; we found that more than half of them co-expressed calbindin (60.5 \pm 4.2 ; Figure 6D) and that some of them co-expressed calretinin (17.3 \pm 5.3 ; Figure $6 \mathrm{E})$. However, similar to what has been described in rats (Varea et al., 2005), none of them co-expressed parvalbumin.

\section{DISCUSSION}

The present results describe a widespread distribution of PSA-NCAM expression in the cerebral cortex of adult cats. In agreement with previous results in rodents, two PSA-NCAM expressing populations can be discriminated. One corresponding to immature neurons located mainly in cortical layer II, the other constituted by mature interneurons present in most of the layers. Our results also indicate that the immature PSA-NCAM expressing neurons in layer II are not recently generated and that they do not appear to have an interneuronal fate.

\section{PSA-NCAM EXPRESSING INTERNEURONS ARE PRESENT IN THE CEREBRAL CORTEX OF ADULT CATS}

The distribution of PSA-NCAM expressing interneurons (L cells) in the cerebral cortex of adult cats is very similar to that described in rodents, in which these cells are present in every cortical region 

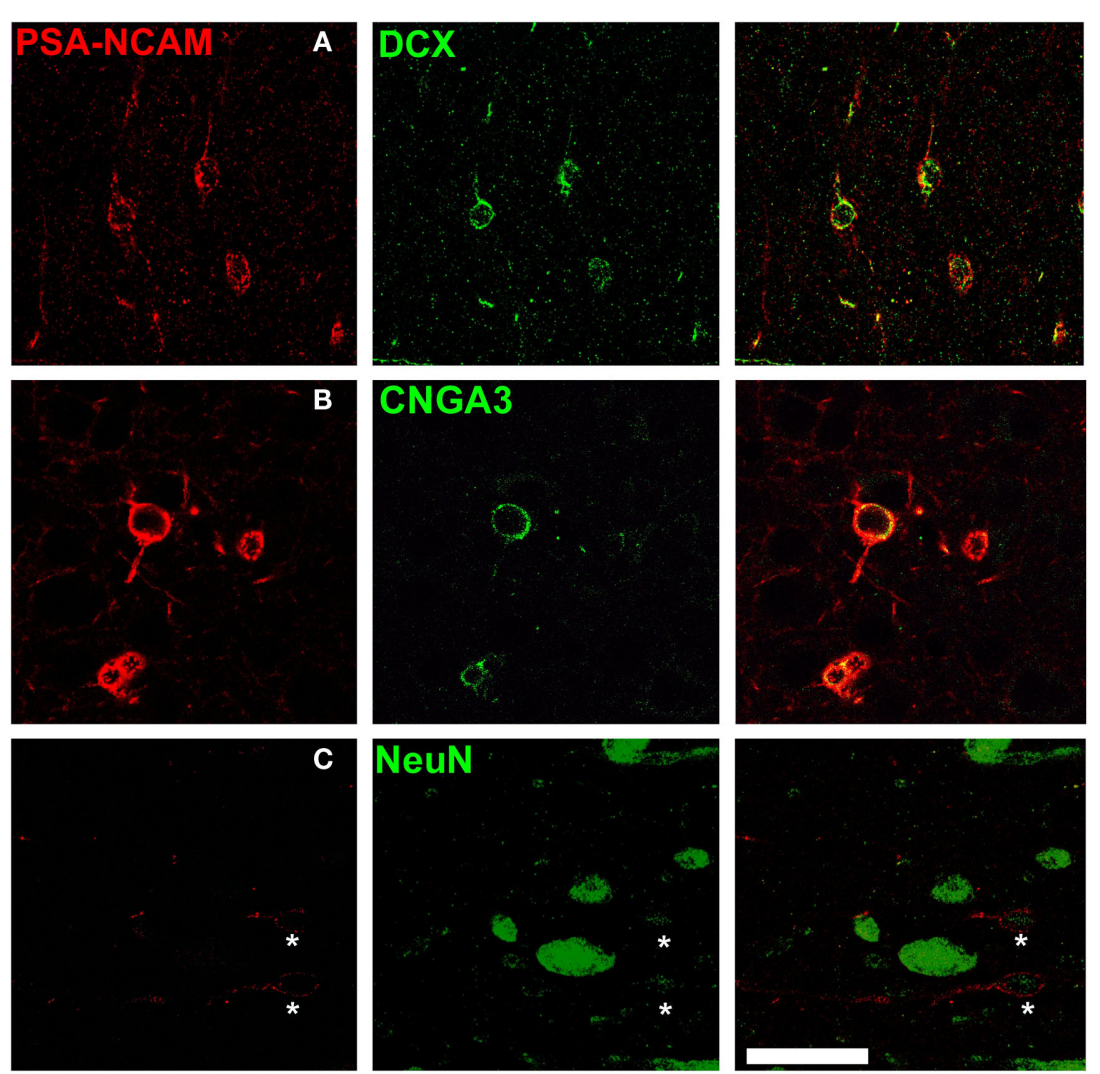

FIGURE 3 | Immature phenotype of PSA-NCAM expressing neurons in the cat cerebral cortex layer II. PSA-NCAM expressing cells in layer II (asterisks) co-express the immature neuronal markers doublecortin (DCX) (A) and the cyclic nucleotide-gated cation channel 3 (CNGA3) (B). Some PSA-NCAM expressing cells in layer II (asterisks) express weakly NeuN, a nuclear marker expressed by mature neurons (C). All the images in this figure are 2D projections of three consecutive confocal planes located $1 \mu \mathrm{m}$ apart. Scale bar: $25 \mu \mathrm{m}$.
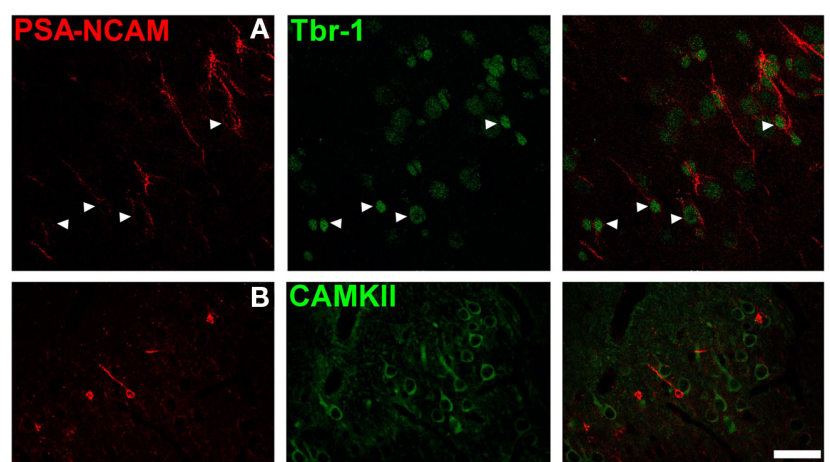

FIGURE 4 | Polysialylated form of the neural cell adhesion molecule expressing neurons in the cat cerebral cortex layer II are immature excitatory neurons. (A) PSA-NCAM expressing cells the cat cerebral cortex layer II co-express Tbr-1, a transcription factor specifically expressed by pallium-derived principal neurons). (B) However, none of them express $\mathrm{Ca}(2+)$ / CaM-dependent protein kinase II (CAMKII), a marker of mature excitatory neurons. All the images in this figure are $2 \mathrm{D}$ projections of three consecutive confocal planes located $1 \mu \mathrm{m}$ apart. Scale bar: $30 \mu \mathrm{m}$.

(Varea et al., 2005; Gomez-Climent et al., 2010a; Nacher et al., 2010). A previous report in adult cats, focused on DCX expression, described the presence of medium to large cells with faint
DCX immunoreactivity in deep cortical layers (Cai et al., 2009). These authors reported that these cells consistently co-express NeuN, a marker of mature neurons (Mullen et al., 1992), and GABA. They also found that these cells in deep cortical layers expressed GAD67, calbindin, somatostatin, NADPH diaphorase, and neural nitric oxide synthase (nNOS) and, consequently, considered them inhibitory neurons. We have not detected this type of low DCX expressing cells neither in the cat material used in the present study nor in our previous studies on rats or mice (Varea et al., 2005; Gomez-Climent et al., 2010a; Nacher et al., 2010). Two possibilities may exist for this discrepancy: The DCX expression level may be under the detection limits of our immunohistochemical technique or the immunoreactivity in these cells may be due to unspecific labeling of interneurons. The second possibility should be tested by performing appropriate controls for immunohistochemistry, blocking primary antiDCX antibodies with their antigenic peptides, which were not performed in the previous report by Cai et al. (2009). Moreover, although these authors erroneously indicated that in a previous study we had found DCX/somatostatin expressing cells in deep cortical layers, we never observed these cells in rats or mice. What we described in rodents was a population of cells expressing PSA-NCAM, but never DCX, which we classified as mature interneurons (Varea et al., 2005; Gomez-Climent et al., 2010a; 

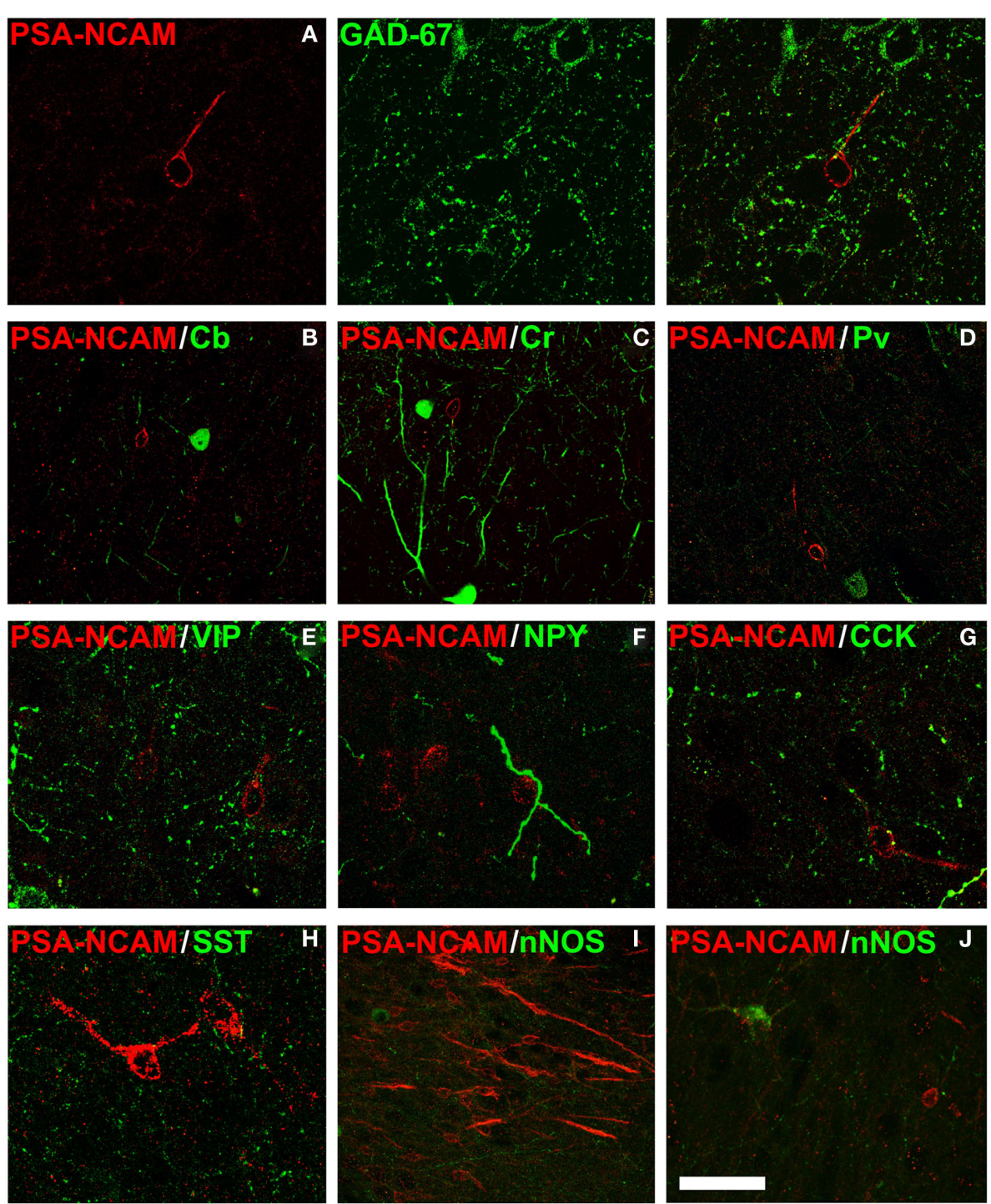

FIGURE 5 | Polysialylated form of the neural cell adhesion molecule expressing neurons in layer II are not interneurons. Lack of colocalization between PSA-NCAM and different markers of interneurons in the cat cerebral cortex layer II: (A) glutamic acid decarboxylase 67 isoform (GAD67), (B) D-28 K Calbindin (Cb), (C) calretinin (Cr), (D) parvalbumin (Pv), (E) vaso-intestinal peptide (VIP), (F) neuropeptide Y (NPY), (G) cholecystokinin (CCK), (H) somatostatin (SST), or (I,J): neural isoform of the nitric oxide synthase (nNOS). All the images in this figure are 2D projections of three consecutive confocal planes located $1 \mu \mathrm{m}$ apart. Scale bar: $25 \mu \mathrm{m}$ for $(\mathbf{A}, \mathbf{E}-\mathbf{H}) ; 50 \mu \mathrm{m}$ for (B-D,J); $75 \mu \mathrm{m}$ for (I).
Nacher et al., 2010). We have found that the population of PSANCAM expressing L cells corresponds to mature interneurons, based on the expression of NeuN and the lack of expression of DCX. These PSA-NCAM expressing L cells are characterized by the expression of different proteins typically found in interneurons, such as calbindin and calretinin, although none of them express parvalbumin. Moreover, they lack CAMKII expression, a marker of excitatory neurons. These results are very similar to those found in the cerebral cortex of rats and humans, in which most PSA-NCAM expressing somata co-express calbindin and none or very few of them co-express parvalbumin (Varea et al., 2005, 2007; Gomez-Climent et al., 2010a).
The PSA-NCAM expression pattern regarding $\mathrm{L}$ cells and neuropil expression is also similar to that of rodents in other regions of the cat CNS, such as the hippocampus, amygdala, hypothalamus, or the olfactory bulb (Nacher et al., 2002b,c, 2010; Bonfanti, 2006).

In summary, PSA-NCAM expressing interneurons in the cat cerebral cortex are similar to those found in the rodent cerebral cortex. Consequently, they may have similar structural characteristics, such as reduced synaptic input and reduced dendritic arborization and spine density as described in rodents (Gomez-Climent et al., 2010a). The expression of PSA-NCAM on cortical interneurons may have important implications on the structure and physiology 

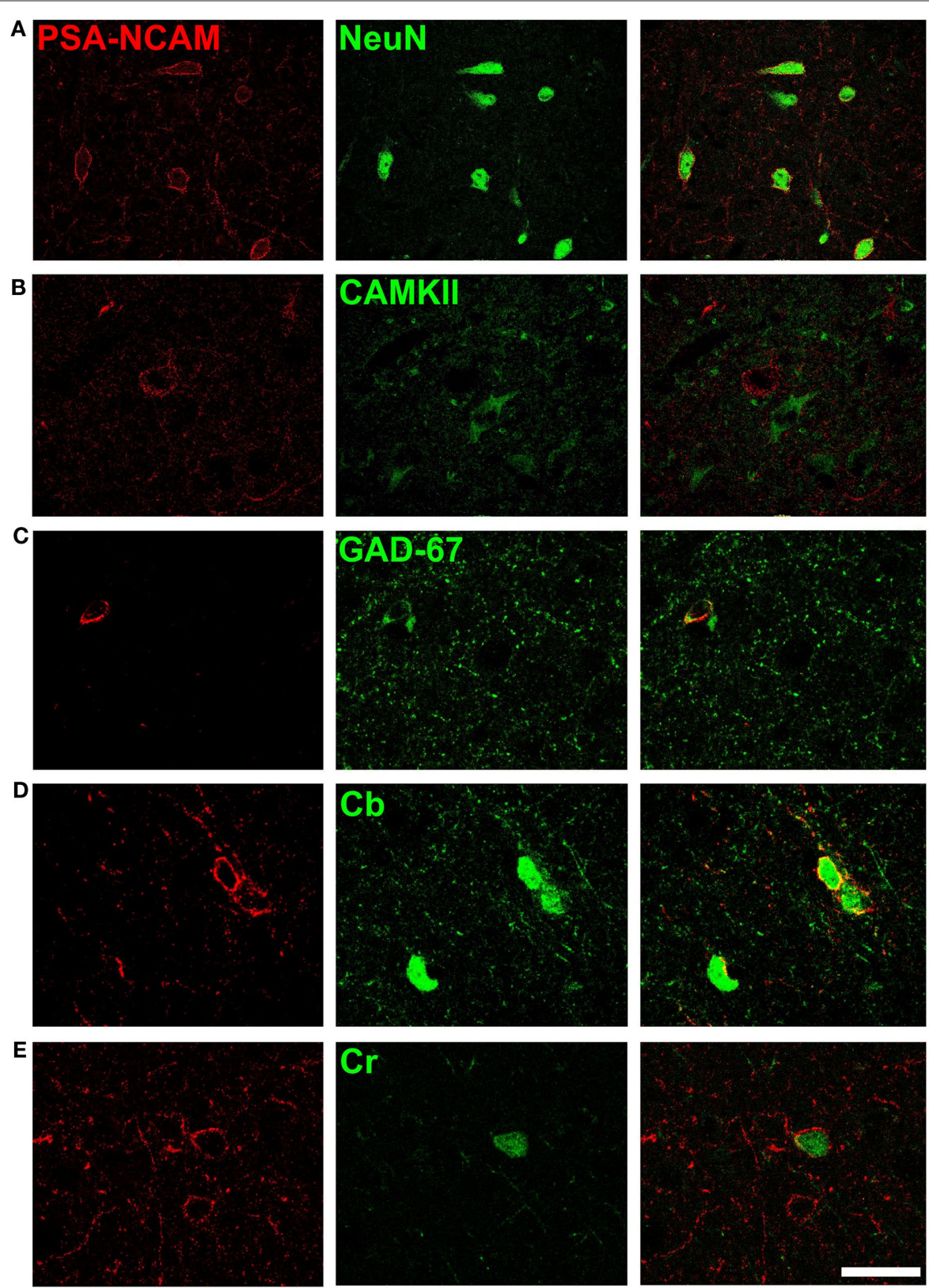

FIGURE 6 | Phenotype of PSA-NCAM expressing neurons in deep layers of the cat cerebral cortex. Neurons expressing PSA-NCAM in deep layers (III-VI) of the cat cerebral cortex co-express $\mathrm{NeuN}(\mathbf{A})$ but they do not co-express $\mathrm{Ca}(2+)$ / CaM-dependent protein kinase II (CAMKII) (B). Many of these cells co-express glutamic acid decarboxylase 67 isoform (GAD67) (C) and the calcium binding proteins D-28k calbindin (Cb) (D) and calretinin (Cb) (E), but none of them express parvalbumin $(\mathrm{PV})$. All the images in this figure are $2 \mathrm{D}$ projections of three consecutive confocal planes located $1 \mu \mathrm{m}$ apart. Scale bar: $25 \mu \mathrm{m}$. of cortical inhibitory circuits. Moreover, it may also be relevant for the understanding of the etiology of certain psychiatric disorders, in which alteration of inhibitory networks has been described.

\section{PSA-NCAM EXPRESSING CELLS IN THE CEREBRAL CORTEX LAYER II OF ADULT CATS ARE IMMATURE NEURONS}

Our present results on the distribution of PSA-NCAM expressing cells in the cerebral cortex layer II of cats are in accordance with that of DCX expressing cells described by Cai et al. (2009). In fact, these authors acknowledged a virtually complete colocalization of DCX and PSA-NCAM in layer II, which we have replicated in our study. A similar widespread distribution has been described in non-human primates, where these cells are also more common in associative rather than in primary cortical regions (Cai et al., 2009; Zhang et al., 2009). The presence of a band of PSA-NCAM expressing cells similar to that found in layer II in rodents can be observed at least in the entorhinal cortex of human infants (Ni Dhuill et al., 1999) and a recent report has described the presence 
of DCX expressing cells in the upper border of cortical layer II of humans of different ages (Cai et al., 2009). This widespread distribution of PSA/DCX expressing cells in layer II of cats and primates is in contrast with that observed in mice and rats, where these cells are mostly restricted to layer II of the piriform and lateral entorhinal cortices. However, scattered cells also populate this layer in the perirhinal, the agranular insular, and the ectorhinal cortices (Seki and Arai, 1991; Nacher et al., 2002a; Bonfanti, 2006; Phillips et al., 2006; Shapiro et al., 2007a,b; Gomez-Climent et al., 2008). In guinea pigs and rabbits DCX/PSA-NCAM expressing cells can be found in layers II and upper III of the piriform, perirhinal, and entorhinal cortices, as well as in the amygdaloid-piriform transitional region. In the neocortex of these animals these cells are located in the somatosensory cortex and different regions of the insula (Bonfanti, 2006; Luzzati et al., 2008; Xiong et al., 2008). The wider distribution of immature neurons in cortical layer II in mammals with larger cerebral cortices, in contrast to that found in rodents or in lizards, restricted to areas primarily related to olfaction (Ramirez-Castillejo et al., 2002; Luzzati et al., 2008), indicates that these cells may participate in some basic processes general to the cerebral cortex and not only to olfactory processing. In this regard, it has been suggested that these immature neurons are preferentially located in higher order associative regions and that they may be involved in non-spatial learning (Luzzati et al., 2008).

The present results concerning the phenotype of PSA-NCAM expressing cells in cortical layer II of adult cats are in partial disagreement with those reported by Cai et al. (2009). There is coincidence in the fact that most of these cells co-express DCX and most of them lack NeuN expression, indicating that, as it occurs in rodents, these cells are mainly immature neurons. This hypothesis is also supported by the expression of cyclic nucleotide-gated ion channel 3 (CNGA3), which is also found in this cell population in rats (Gomez-Climent et al., 2008). However, despite the fact that most, if not all, PSA-NCAM expressing cells in layer II co-express DCX, we have failed to find any of them co-expressing markers of interneurons. We have studied the expression of different calcium binding proteins and nNOS expression and none of these proteins can be detected in the PSA-NCAM expressing S cells of layer II. Moreover, PSA-NCAM expressing $S$ cells in the cat cortical layer II co-express the transcription factor Tbr-1, which is specific for pallium-derived principal neurons and is also expressed by most immature neurons in the cortical layer II of mice, rats, rabbits, and guinea pigs (Luzzati et al., 2008). These results do not support those of Cai et al. (2009) suggesting that most immature neurons in cortical layer II are progressively differentiating into interneurons. By contrast, they are in agreement to previous results obtained in other mammals using the same markers of interneurons and transcription factors, which suggest an excitatory fate. However, It has to be noted that, as it occurs in rats (Gomez-Climent et al.,

\section{REFERENCES}

Abrous, D. N., Montaron, M. F., Petry, K. G., Rougon, G., Darnaudery, M., Le Moal, M. and Mayo, W. (1997). Decrease in highly polysialylated neuronal cell adhesion molecules and in spatial learning during ageing are not correlated. Brain Res. 744, 285-292.

Bonfanti, L. (2006). PSA-NCAM in mammalian structural plasticity and neurogenesis. Prog. Neurobiol. 80, 129-164. Cai, Y., Xiong, K., Chu, Y., Luo, D. W., Luo, X.G., Yuan, X.Y., Struble, R. G., Clough,
2008), PSA-NCAM expressing cells in the cat cortical layer II do not co-express CAMKII, a marker of mature excitatory neurons, indicating that they are not yet fully differentiated as long as they present PSA-NCAM expression.

Despite all these data supporting an excitatory fate for most immature neurons in cortical layer II, the possibility that a small number of these cells may become interneurons cannot be ruled out, since in other species a very restricted population of these cells express DLL, a transcription factor specifically found in subpallium-derived interneurons (Luzzati et al., 2008).

\section{ORIGIN OF IMMATURE NEURONS IN THE CEREBRAL CORTEX LAYER II OF ADULT CATS}

We have failed to find evidence that immature neurons in the cortical layer II of adult cats are recently generated. Consequently, it is likely that most of these cells were generated during development, as it occurs in rats (Gomez-Climent et al., 2008). In these rodents, immature neurons in cortical layer II are mainly generated during embryonic development and remain in an immature stage into adulthood. However, it is possible, that low numbers of these cells are generated during adulthood, as it has been described in rats and mice (Pekcec et al., 2006; Shapiro et al., 2007a,b). However, the origin of these immature neurons remains uncertain. A recent report has suggested layer I as a putative niche for these newly generated cells in guinea pigs (Xiong et al., 2010). Moreover, the production of pyramidal neurons from NG2 expressing oligodendrocyte progenitors has been described in the adult mouse piriform cortex layer II (Rivers et al., 2008; Guo et al., 2010). Interestingly, these authors, using $5^{\prime} \mathrm{BrdU}$ labeling found that the vast majority of these pyramidal neurons was not recently generated, which is in accordance with our results in rodents and cats.

In summary, given their abundance and their presence in different cortical areas, this population of immature neurons in layer II may have important implications in our understanding of the cortical circuitry. As the current data suggest, they may progressively incorporate to cortical networks rather than die. Although initially these immature neurons were related to olfaction, since in rodents they are located principally in olfactory related regions, their distribution in mammals with larger cerebral cortices suggests a more general function. Whether the integration of these cells is continuous or whether it responds to certain stimuli still remains to be elucidated.

\section{ACKNOWLEDGMENTS}

Spanish Ministry of Science and Innovation (MICINN-FEDER) BFU2009-12284/BFI (Juan Nacher) and BFU2007-64130/BFI (Carlos Crespo), Generalitat Valenciana CS2009-AP-127 and ACOMP2009/271 (Juan Nacher), and Jerome Lejeune Foundation (Emilio Varea).
R. W., Spencer, D. D., Williamson, A., Kordower, J.H., Patrylo, P. R., and Yan, X.X. (2009).Doublecortin expression in adult cat and primate cerebral cortex relates to immature neurons that develop into GABAergic subgroups. Exp. Neurol. 216, 342-356.
Csiffary, A., Gorcs, T. J., and Palkovits, M. (1990). Neuropeptide Y innervation of ACTH-immunoreactive neurons in the arcuate nucleus of rats: a correlated light and electron microscopic double immunolabeling study. Brain Res. 506, 215-222. 
Friedman, B., and Price, J. L. (1986). Agedependent cell death in the olfactory cortex: lack of transneuronal degeneration in neonates. J. Comp. Neurol. 246, 20-31.

Gomez-Climent, M. A., Castillo-Gomez, E., Varea, E., Guirado, R., BlascoIbanez, J. M., Crespo, C., MartinezGuijarro, F. J., and Nacher, J. (2008). A population of prenatally generated cells in the rat paleocortex maintains an immature neuronal phenotype into adulthood. Cereb. Cortex 18, 2229.

Gomez-Climent, M. A., Guirado, R., Castillo-Gomez, E., Varea, E., Gutierrez-Mecinas, M., Gilabert-Juan, J., Garcia-Mompo, C., Vidueira, S., Sanchez-Mataredona, D., Hernandez, S., Blasco-Ibanez, J. M., Crespo, C., Rutishauser, U., Schachner, M., and Nacher, J. (2010a). The polysialylated form of the neural cell adhesion molecule (PSA-NCAM) is expressed in a subpopulation of mature cortical interneurons characterized by reduced structural features and connectivity. Cereb. Cortex. PMID:20843898. [Epub ahead of print].

Gomez-Climent, M. A., Guirado, R., Varea, E., and Nacher, J. (2010b). Arrested development. Immature, but not recently generated, neurons in the adult brain. Arch. Ital. Biol. 148 $159-172$

Guo, F., Maeda, Y., Ma, J., Xu, J., Horiuchi, M., Miers, L., Vaccarino, F., and Pleasure, D. (2010). Pyramidal neurons are generated from oligodendroglial progenitor cells in adult piriform cortex. J. Neurosci. 30, 12036-12049.

Gutierrez-Mecinas, M., Crespo, C., Blasco-Ibanez, J. M., Nacher, J., Varea, E., and Martinez-Guijarro, F. J. (2007). Migrating neuroblasts of the rostral migratory stream are putative targets for the action of nitric oxide. Eur. J. Neurosci. 26, 392-402.

Kempermann, G. (2005). Adult Neurogenesis. Oxford: Oxford University Press.

Lantos, T. A., Gorcs, T. J., and Palkovits, M. (1995). Immunohistochemical mapping of neuropeptides in the premamillary region of the hypothalamus in rats. Brain Res. Brain Res. Rev. 20, 209-249.

Luzzati, F., Bonfanti, L., Fasolo, A., and Peretto, P. (2008). DCX and PSA-NCAM expression identifies a population of neurons preferentially distributed in associative areas of different pallial derivatives and vertebrate species. Cereb. Cortex 19, 1028-1041.

Mullen, R. J., Buck, C. R., and Smith, A. M. (1992). NeuN, a neuronal specific nuclear protein in vertebrates. Development 116, 201-211.

Murphy, K. J., Fox, G. B., Foley, A. G., Gallagher, H. C., O'Connell, A. Griffin, A. M., Nau, H., and Regan, C. M. (2001). Pentyl-4-yn-valproic acid enhances both spatial and avoidance learning, and attenuates age-related NCAM-mediated neuroplastic decline within the rat medial temporal lobe. J. Neurochem. 78, 704-714.

Nacher, J., Alonso-Llosa, G., Rosell, D. R., and McEwen, B. S. (2002a). PSANCAM expression in the piriform cortex of the adult rat. Modulation by NMDA receptor antagonist administration. Brain Res. 927, 111-121.

Nacher, J., Blasco-Ibanez, J. M., and McEwen, B. S. (2002b). Non-granule PSA-NCAM immunoreactive neurons in the rat hippocampus. Brain Res. 930 1-11.

Nacher, J., Lanuza, E., and McEwen, B. S. (2002c). Distribution of PSA-NCAM expression in the amygdala of the adult rat. Neuroscience 113, 479-484.

Nacher, J., Guirado, R., Varea, E., AlonsoLlosa, G., Rockle, I., and Hildebrandt, H. (2010). Divergent impact of the polysialyltransferases ST8SiaII and ST8SiaIV on polysialic acid expression in immature neurons and interneurons of the adult cerebral cortex. Neuroscience 167, 825-837.

Ni Dhuill, C., Fox, G. B., Pittock, S. J., O'Connell, A. W., Murphy, K. J., and Regan, C. M. (1999). Polysialylated neural cell adhesion molecule expression in the dentate gyrus of the human hippocampal formation from infancy to old age. J. Neurosci. Res. 55, 99-106.

Pekcec, A., Loscher, W., and Potschka, H. (2006). Neurogenesis in the adult rat piriform cortex. Neuroreport 17 571-574.

Phillips, W., Jennifer, M. A., and Barker, R. A. (2006). Limbic neurogenesis/ plasticity in the R6/2 mouse model of Huntington's disease. Neuroreport $17,1623-1627$.

Ramirez-Castillejo, C., Nacher, J., Molowny, A., Ponsoda, X., and LopezGarcia, C. (2002). PSA-NCAM immunocytochemistry in the cerebral cortex and other telencephalic areas of the lizard Podarcis hispanica: differential expression during medial cortex neuronal regeneration. J. Comp. Neurol. 453, 145-156.

Reinoso-Suarez, F. (1961). Topographischer Hirnatlas der katze. Darmstadt: Herausgegeben von E. Merck AG.

Rivers, L. E., Young, K. M., Rizzi, M., Jamen, F., Psachoulia, K., Wade, A., Kessaris, N., and Richardson, W. D. (2008). PDGFRA/NG2 glia generate myelinating oligodendrocytes and piriform projection neurons in adult mice. Nat. Neurosci. 11, 1392-1401.

Rougon, G., Dubois, C., Buckley, N. Magnani, J. L., and Zollinger, W. (1986).A monoclonal antibody against meningococcus group B polysaccharides distinguishes embryonic from adult N-CAM. J. Cell Biol. 103, 2429-2437.

Rutishauser, U. (2008). Polysialic acid in the plasticity of the developing and adult vertebrate nervous system. Nat. Rev. Neurosci. 9, 26-35.

Sarma, A. A., Richard, M. B., and Greer C. A. (2010). Developmental dynamics of piriform cortex. Cereb. Cortex. doi: 10.1093/cercor/bhq199. [Epub ahead of print].

Seki, T., and Arai, Y. (1991). Expression of highly polysialylated NCAM in the neocortex and piriform cortex of the developing and the adult rat. Anat. Embryol. (Berl.) 184, 395-401.

Shapiro, L. A., Ng, K. L., Kinyamu, R., Whitaker-Azmitia, P., Geisert, E. E., Blurton-Jones, M., Zhou, Q. Y., and Ribak, C.E. (2007a). Origin, migration and fate of newly generated neurons in the adult rodent piriform cortex. Brain Struct. Funct. 212, 133-148.

Shapiro, L. A., Ng, K. L., Zhou, Q. Y., and Ribak, C.E. (2007b). Olfactory enrichment enhances the survival of newly born cortical neurons in adult mice. Neuroreport 18, 981-985.

Varea, E., Castillo-Gomez, E., GomezCliment, M. A., Blasco-Ibanez, J. M. Crespo, C., Martinez-Guijarro, F. J., and Nacher, J. (2007). PSA-NCAM expression in the human prefrontal cortex. J. Chem. Neuroanat. 33 202-209.

Varea, E., Castillo-Gomez, E., GomezCliment, M. A., Guirado, R. Blasco-Ibañez, J. M., Crespo, C., Martinez-Guijarro, F. J., and Nacher J. (2009). Differential evolution of PSA-NCAM expression during aging of the rat telencephalon. Neurobiol. Aging 30, 11.
Varea, E., Nacher, J., Blasco-Ibanez, J. M., Gomez-Climent, M. A., Castillo-Gomez, E., Crespo, C., and Martinez-Guijarro, F. J. (2005). PSANCAM expression in the rat medial prefrontal cortex. Neuroscience 136, 435-443.

Xiong, K., Cai, Y., Zhang, X. M., Huang, J. F., Liu, Z. Y., Fu, G. M., Feng, J. C., Clough, R. W., Patrylo, P. R., Luo, X. G., Hu, C. H., and Yan, X. X. (2010). Layer I as a putative neurogenic niche in young adult guinea pig cerebrum. Mol. Cell. Neurosci. 45, 180-191.

Xiong, K., Luo, D. W., Patrylo, P. R., Luo, X. G., Struble, R. G., Clough, R. W. and Yan, X. X. (2008). Doublecortinexpressing cells are present in layer II across the adult guinea pig cerebral cortex: partial colocalization with mature interneuron markers. Exp. Neurol. 211, 271-282.

Zhang, X. M., Cai, Y., Chu, Y., Chen, E. Y., Feng, J. C., Luo, X. G., Xiong, K., Struble, R. G., Clough, R. W., Patrylo, P. R., Kordower, J. H., and Yan, X. X. (2009). Doublecortin-expressing cells persist in the associative cerebral cortex and amygdala in aged nonhuman primates. Front. Neuroanat. 3:17. doi: 10.3389/neuro.05.017.2009

Conflict of Interest Statement: The authors declare that the research was conducted in the absence of any commercial or financial relationships that could be construed as a potential conflict of interest.

Received: 01 January 2011; paper pending published: 17 January 2011; accepted: 31 January 2011; published online: 15 February 2011.

Citation: Varea E, Belles M, Vidueira S, Blasco-Ibáñez JM, Crespo C, Pastor AM and Nacher J (2011) PSA-NCAM is expressed in immature, but not recently generated, neurons in the adult cat cerebral cortex layer II. Front. Neurosci. 5:17. doi. 10.3389/fnins.2011.00017

This article was submitted to Frontiers in Neurogenesis, a specialty of Frontiers in Neuroscience.

Copyright (c) 2011 Varea, Belles, Vidueira, Blasco-Ibáñez, Crespo, Pastor and Nacher. This is an open-access article subject to an exclusive license agreement between the authors and Frontiers Media SA, which permits unrestricted use, distribution, and reproduction in any medium, provided the original authors and source are credited. 